\title{
Constraining Factors of Research among faculty members at Hormozgan University of Medical Sciences
}

\author{
Azim Nejatizadeh $^{1}$, Majid Sarnayzadeh ${ }^{2}$, Kobra Kahnouji $^{3}$, Rachel Ghasemi ${ }^{4}$, Nahid Nakhodaei ${ }^{5}$
}

${ }^{1}$ Ph.D. Associate Professor, Department of Research and Technology, Hormozgan University of Medical Sciences, Bandar Abbas, Iran

${ }^{2}$ M.Sc., Social Determinants in Health Promotion Research Center, Hormozgan University of Medical Sciences, Bandar Abbas, Iran

${ }^{3}$ M.Sc., Health Information Management Research Center, Hormozgan University of Medical Sciences, Bandar Abbas, Iran

${ }^{4}$ M.Sc., Department of Research and Technology, Hormozgan University of Medical Sciences, Bandar Abbas, Iran

${ }^{5}$ B.Sc., Department of Research and Technology, Hormozgan University of Medical Sciences, Bandar Abbas, Iran

\section{Type of article: Original}

\begin{abstract}
Introduction: In recent decades, the major criteria for development in countries were defined mostly by research position. The first step in organizing the research subject in societies is gaining a correct perception of abilities, available facilities, and finding the strengths and weaknesses of research programs. This research was conducted to determine the constraining factors of research among faculty members.

Methods: In this cross-sectional study in 2013, the population was Hormozgan Medical Science faculty members, and samples were selected based on the Morgan table (138 individuals). A researcher-made questionnaire after determining validity and confirming reliability was distributed among them. The data were analyzed by SPSS using descriptive and inferential statistics, such as Pearson's product-moment correlation.

Results: Among organizational factors, lack of data presentation to researchers from organization sections with $81.2 \%$ was the most effective factor. The lack of facilitating national and international research exchange with $80.5 \%$ and the lack of research workshops based on needs with $77.9 \%$ were the next ones. Among the personal constraining factors, $64 \%$ of the faculty declared that having inadequate time for research due to the educational activities was the main factor.

Conclusions: According to the faculty's comments, research activities encounter different constraining factors. It can be said that, by promoting a data registration system, collaborating on contract agreements and improving national and international research exchange, empowering members' research (need-based workshops), and decreasing the faculty's clinical and educational activities can overcome these constraints.

Keywords: Obstacles, Research, Faculty
\end{abstract}

\section{Introduction}

\subsection{Background}

Science, research, culture, and politics are related issues for which evolution in each cannot be true and stable without coordinating with the others. Research is a main subject in national immunity in any country (1). Based on their spiritual and material capacities, universities are counted among the most significant science production centers, so organizing university research is one of the main factors in developing any country comprehensively (2).

\subsection{Statement of Problem and objectives}

Currently, science production and distribution as one of the most vital tasks of any scientific section, and it encompasses a great deal of country scientific situations and university faculty members as the main elements of

\section{Corresponding author:}

Kobra Kahnouji, Health Information Management Research Center, Hormozgan University of Medical Sciences, Bandar Abbas, Iran. Tel: +98.7633337192, Fax: +98.7633337192, Email: kahnooji56@gmail.com

Received: December 18, 2015, Accepted: April 08, 2016, Published: May 2016

iThenticate screening: April 08, 2016, English editing: April 18, 2016, Quality control: May 04, 2016

(C) 2016 The Authors. This is an open access article under the terms of the Creative Commons Attribution-NonCommercialNoDerivs License, which permits use and distribution in any medium, provided the original work is properly cited, the use is non-commercial and no modifications or adaptations are made. 
education and research, and it has a serious task in scoring this subject (3). One of the main ways of progressing any country is caring about the research issue and increasing its activities and especially university faculty's motivation increment in order to conduct scientific research. Despite developed countries, scientific research in developing countries is few and research human resources, budget, and facilities are poor (4). Currently, industrial and developing countries are trying to increase their research capital. Industrial countries are increasing their research capital to protect and continue their situation, or they are increasing their salience in international competition and developing countries, adhering to the truth that the main way to gain stable development and growth is research capital (5). At health organizations and medical universities, the major research activities are accomplished by graduate students and their supervisors. The efficiency of these organizations and universities can be assessed by three principal segments, i.e., healthcare, teaching, and research activities, due to their interconnectedness. To improve and plan research policies in such organizations, it is necessary to evaluate their research activities. This assessment leads to proper planning on financial, human, and material resources, which causes the development and growth of the institution (6). Many studies in different systems, such as management, higher education, information systems, agriculture, and medical and health systems focus mainly on exploration of promoting factors and improving research productivity. These promoting factors are classified into two groups, i.e., individual and institutional factors (7). In past years, problems for research in developing countries didn't aim for solutions, because it was implicated and applied from the solutions in western countries. As the researchers lack the qualification and required skills for conducting a research, the research quality is affected by these issues and still underdeveloped and poor (8). The first step in organizing a research subject in society is reaching a proper perception of available abilities and facilities and also determining the strengths and weaknesses of research projects (9). Identification the research constraints with better relationship between researchers and research finding users, which ease up the problem-solving process, cause the practical use of research findings, and result in awareness of constraints are essential in resolving them in order to promote the qualitative and quantitative quality of research (10). The objective of this research was to determine the University of Medical Sciences Faculty members' research constraints according to them and to determine how to increase their motivation to conduct more research.

\section{Material and methods}

\subsection{Research design and setting}

In this cross-sectional study in 2013, the population was Hormozgan faculty members who had been working more than one year and including 220 regular employees, contractive, and commitment members of three schools, including Medicine, Health and Nursing-Midwifery-Paramedical. According to the Morgan table, a statistical sample including 138 members was determined.

\subsection{Measurement tool, reliability, and validity}

The questionnaire was designed based on the study of previous studies in other universities and different scientific references. This questionnaire consists of several parts, including demographic information, the main questions (about the research constraints), questions about the partnership, and presenting suggestions and ideas. The main questions are mentioned in two parts, personal and organizational constraints, which were set based on the Likert scale according to the members' ideas in five options (from "strongly disagree" to "strongly agree"). In the first step, this questionnaire was distributed among some of the members accidentally, and, after collecting them, the questions which had ambiguity were demystified and then added to the questionnaire again, and, finally, the main questionnaire was designed. At the end of the questionnaire, members were asked to provide their ideas and suggestions. The questionnaire was concluded with its questions. With the study of credited references and 15 expert ideas, the questionnaire's content and face validity were confirmed. The questionnaire's reliability was determined by means of SPSS software and Cronbach's alpha coefficient, and the internal stability was confirmed, which, by investigating 25 questionnaires, the number of 80 was determined as the result. Questionnaires were distributed anonymously. Different methods were used to distribute the questionnaires. In some sections, the questionnaires were distributed directly or by email or post. Returning the questionnaires took a hard try, and, finally, 115 of 150 questionnaires were returned. In the final analysis, we only included 108 of the completed questionnaires.

\subsection{Statistical analyses}

The data were entered into SPSS software and analyzed by means of descriptive statistics, such as average, standard deviation, and inferential statistics, such as the Pearson product-moment correlation. 


\section{Results}

\subsection{Demographic information}

From the 150 distributed questionnaires, 108 completed questionnaires were entered into SPSS software and analyzed. Among the analyzed questionnaires, $48 \%$ of responders were men, $42 \%$ were women and the remaining did not respond. The average age was 35, and the average experience was seven years. The faculty members who had a Master of Science degree were 29\%, and those with the Ph.D. degree, clinical expertise, and a specialty were 41,9 , and $15 \%$, respectively. The average of faculty members' research activities per person was assessed based on eight activities, i.e., research projects, attendance at national congresses, attendance at international congresses, presentations, published articles, inventions, books, and translations, which were 2.6, 3.5, 0.7, 3.2, 3.7, 0.03, 0.4, and 0.27 , respectively.

\subsection{Organizational and personal constraints}

According to the comments of Hormozgan Medical Sciences University faculty members concerning personal and organizational constraints, the major factor for not doing research was the lack of collaboration with other sections in presenting data to the researchers $(82.1 \%)$, afterwards were the poor national and international research exchange with $(80.5 \%)$, and lack of research workshops based on needs (78\%). Among organizational constraining factors, failure to present proper data to researchers from university other sections (82.1\%) was the most effective, and failure to relate to indoor and outdoor researchers (80.5\%), and also educational workshops needs assessment (78\%) were the latter. Among personal constraints, lack of time was cited by a majority of faculty members, of which $64 \%$ claimed that educational activities consumed most of their time, resulting in limited time for research, whereas administrative activities and clinical activities with 57\% and 54\%, respectively, followed. Among the men, $87.5 \%$ claimed that failure to relate to indoor and outdoor researchers has the priority, and $83.5 \%$ of women's constraints priority claim was the failure to present proper data to researchers from university other sections. Among personal constraints, men's priority was administrative activities by $73 \%$, and women's priority was clinical activities by $64.3 \%$. Effective research constraints in three different schools were calculated, and the results are presented in Table 1.

Table 1. Research constraints in different colleges

\begin{tabular}{|l|l|l|l|l|}
\hline Colleges & Personal Constraints & $\%$ & Organizational Constraints & $\%$ \\
\hline Medicine School & Educational activities & 67.4 & $\begin{array}{l}\text { Lack of national and international } \\
\text { research exchange }\end{array}$ & 88.6 \\
\hline $\begin{array}{l}\text { Nursing, Midwifery and } \\
\text { Paramedical School }\end{array}$ & Educational activities & 84.6 & $\begin{array}{l}\text { Lack of workshops based on faculty } \\
\text { members' needs }\end{array}$ & 92.3 \\
\hline Health School & Administrative activities & 62.5 & $\begin{array}{l}\text { Lack of decision making based on } \\
\text { research results }\end{array}$ & 87.5 \\
\hline
\end{tabular}

\section{Discussion}

Research can be effective in university faculty members being up-to-date and also can be the base of effective and applicable education. The first factor of research constraints according to Hormozgan Medical Sciences University faculty members, was failure of other sections in providing needed data, which was similar to the results obtained by Sohrabi and Farajollahi (11) and Rezaeian et al. in Rafsanjan (12). The next constraints were the poor national and international research exchange and also failure to attend research workshops based on needs. These constraints are organizational constraints that show the importance of these factors according to Hormozgan Medical Sciences University faculty members, which is more matched with Sereshti's research results in Shahrekord (13) and Alamdari's in Yasuj (4), but it is different with Sabzevari in Kerman (14) which gives the priority to average score of personal constraints. Failure to facilitate national and international research exchanges was considered as a constraint according to Hormozgan Medical Sciences University faculty members. Research activities experience in other countries represent any mobility in scientific development, including educational, research, IT, and its qualitative and quantitative promotion is postponed to mutual cooperation between scientific and technological countries and also cooperation and absorbing leading scientists who are in relation with today's science. It seems that providing facilities for holding indoor and outdoor scientific seminars, technological and scientific contract coagulation, faculty members' scientific and international trips, and using research opportunities are among the ways for developing relationship between them and indoor and outdoor researchers. Failure to need assessment for educational workshops is one of the research constraints that can be resolved by providing need assessment forms and distributing them among faculty members to determine their needs and develop workshops based on their needs. Although lack of funds for research was one of the most significant factors in some projects $(5,7,13,15,16)$, this 
subject doesn't have an important role. The research results showed that a great percentage of Medical Sciences University faculty members mainly focus on educational issues and clinical services, so many Medical Sciences University faculty members in developing countries don't have enough time for research (13).

In this research, among the personal constraints, the lack of time due to educational work, clinical work, and administrative activities was cited as the main constraint by a majority of faculty members. In similar research in Arak and Hamedan Universities, according to their faculty members, the main constraint was lacking enough time and consuming it for education, teaching, and clinical services $(3,5)$. Also, the research findings in a study done at Gilan University showed that job- and expertise-related factors were the second constraints according to its faculty members, and $65 \%$ of them claimed that, at this university, education has priority over research (17). In a study by Alghanim and Alhamali, the results indicated that the lack of time, lack of research assistants, lack of funds for research, and being busy with teaching load were the most cited constraints for conducting scientific research (7). Pawar et al., in their research among resident doctors in a tertiary-care hospital, indicated that, lack of time (74\%), lack of research curriculum (42\%), and inadequate facilities (38\%) were the main constraints to pursuing research (18). A 2009 study by Eriko Sumi and a 2012 study by Al-Abdullateef showed that one of the major constraints for conducting research was lack of time $(19,20)$. So, it can be concluded that reducing teaching time; improving existing regulations; and avoiding concomitant clinical, educational and research activities could lead to more research involvement. This research was conducted only among faculty members, and it is necessary to ask the ideas of residents, students, and other personnel. This research only checked the inner organizational constraints in a situation that many of constraints can be affected by factors outside of the organization.

\section{Conclusions}

The research results showed that organizational constraints have the most priority in comparison with personal priorities in research activities. In addition, lack of time and teaching, therapy, and office occupations are among the constraints, which is the answer of the greatest percentage of the faculty members. By promoting information registration system, contact and contract with inner and outer researchers, promotion of faculty research abilities (need assessment-based workshops), and decreasing teaching and therapy activities, can promote health research among faculty members.

\section{Acknowledgments:}

The authors gratefully acknowledge the faculty members who participated in this study. They also extend their appreciation to the Department of Research and Technology, Hormozgan University of Medical Sciences for funding the work.

\section{Conflict of Interest:}

There is no conflict of interest to be declared.

\section{Authors' contributions:}

All authors contributed to this project and article equally. All authors read and approved the final manuscript.

\section{References:}

1) Zohoor AR, Fekry AR. The viewpoint of faculty members on research barriers at Iran University. Payesh. 2003; 2(2): 113-20.

2) Karimian Z, Sabbaghian Z, Salehi A, Sedghpour BS. Internal Obstacles in Research Activities: Faculty Members' Viewpoints in Shiraz University of Medical Sciences. IJME. 2012; 11(7): 750-63. PMID: 23301377.

3) Koorki M, Mahjub H, Sheikh N. Study of the Academic Members Attitude about Main Factors of Not Approaching to Scientific Writing in Hamadan University of Medical Sciences. Scientific J Hamadan Univ Med Sci. 2006; 14(4): 59-63.

4) Alamdari A, Afsoon A. Obstacles in doing research activities opinion of Faculty Members of Yasoge Universities. Armaghan Danesh J. 2003; 29: 27-34.

5) Rafiei M, Jahani F. Effective factors on writing of Persian and non-Persian articles in Arak University of Medical Sciences faculty members' point of view in 2008. AMUJ. 2009; 12(2): 61-72.

6) Tess BH, Furuie SS, Castro RCF, Barreto MCC, Nobre MRC. Assessing the scientific research productivity of a Brazilian healthcare institution: a case study at the Heart Institute of São Paulo, Brazil. 
Clinics. 2009; 64(6): 571-6. doi: 10.1590/S1807-59322009000600013. PMID: 19578662, PMCID: PMC2705144.

7) Alghanim SA, Alhamali RM. Research productivity among faculty members at medical and health schools in Saudi Arabia. Prevalence, obstacles, and associated factors. Saudi Med J. 2011; 32(12): 1297-303. PMID: 22159387.

8) Sabzwari S, Kauser S, Khuwaja AK. Experiences, attitudes and barriers towards research amongst junior faculty of Pakistani medical universities. BMC Med Educ. 2009; 9: 68. doi: 10.1186/1472-6920-9-68. PMID: 19917109, PMCID: 2780986.

9) Badrizadeh A, Gholami Y, Birjandi M, Beiranvand G, Mahooti F. Barriers to research from viewpoint of faculty members of Lorestan university of medical sciences. YJMS. 2009; 11(3): 93-100.

10) Nikrouz L, Roozitalab M, RayeganShirazi AR, Naghizadeh MM, Taghavi F. Student Research Projects Inhibiting Factors from the Students Perspective. JFUMS. 2012; 2(2): 113-119.

11) Sohrabi Z, Farajollahi M. Research Problems from Educational boards' view of Iran University of medicalSciences. J Med Counc I R. 2009; 27(2): 175-9.

12) Rezaeian M, AsadpourM, HadaviM. Research Barriers from the Perspective of Academic Members and Strategies for Confronting with These Barriers in Rafsanjan University of Medical Sciences, Iran. J Health Syst Res. 2013; 9(3): 269-76.

13) Sereshti M, Kazemian A, Daris F. Research barriers from the viewpoint of faculty members and employees of Shahrekord University of Medical Sciences. Iranian Journal of Educational Strategies. 2010; 3(2): 51 -7.

14) Sabzevari S. AliZadeh S. Azizzadeh F. Comments of faculty members of Kerman universities on barriers to research activities. The Journal of Shahid Sadoughi University of Medical Sciences. 2000; 8(2): 17-27.

15) Karimi A, Mehdipour Y, Mohammadpour A, Pirozanfar S. The Study of Constraining Factors of Research from the Viewpoint of Faculty Members of Zahedan University of Medical Sciences. Health Information Management. 2011; 7(4): 474.

16) Dadkhah B, Mohammadi M, Poornaseri S, Mozaffari N, Adham D. View of Ardabil Province Universities Scientific Members' about research and its Limitations. J Ardabil Univ Med Sci. 2008; 8(1): 37-44.

17) Farmanbar R, Asgari F. Survey of negativefactors for doing research Faculty Members Point of View of Gilan Medical SciencesUniversity. Gilan Medical Faculty J. 2005; 54(14): 84-90.

18) Pawar DB, Gawde SR, Marathe PA. Awarenessabout medical research among resident doctors in a tertiary care hospital: A cross-sectional survey. Perspect Clin Res. 2012; 3: 57-61. doi: 10.4103/2229-3485.96446. PMID: 22701821, PMCID: 3371549.

19) Sumi E, Murayama T, Yokode M. A survey of attitudes toward clinical research among physicians at Kyoto University Hospital. BMC Med Educ. 2009; 22: 9-75. doi: 10.1186/1472-6920-9-75. PMID: 20025782, PMCID: 2805647.

20) Al-Abdullateef SH. A survey of the attitude and practice of research among doctors in Riyadh Military Hospital primary care centers, Saudi Arabia. J Fam Community Med. 2012; 19: 38-42. doi: 10.4103/22308229.94012. PMID: 22518357, PMCID: 3326769. 